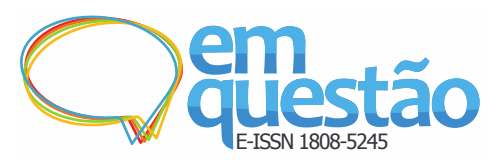

\section{Entrecruzamento dos estudos geracionais e a formação de usuários}

\author{
Marcos Aurelio Gomes \\ Doutor; Universidade Federal de Alagoas, Maceió, AL, Brasil; \\ marcosaureliog@gmail.com
}

\begin{abstract}
Resumo: Objetiva identificar as conexões históricas e sociais entre os estudos de gerações e as práticas desenvolvidas no uso dos recursos informacionais pelas bibliotecas. Estudo de natureza exploratória com enfoque na pesquisa bibliográfica. Quatro categorias foram estabelecidas: coorte; características; tempo histórico e social; e formação dos usuários. Ao se considerar tais categorias, delineou-se o cenário para cada classe geracional: veteranos, baby boomers e as gerações X, Y e Z. Conclui-se que cada classe geracional indica, em determinado tempo, uma possível correspondência direta com a formação de usuários da informação, essa, por sua vez, condicionada a uma demanda socioeconômica.
\end{abstract}

Palavras-chave: Educação de usuários. Estudos de usuários. Formação de usuários.

\section{Introdução}

A sociedade vive momentos de mudanças que permitem situar as gerações em uma complexa condição biossocial. Compreende-se que os aspectos econômicoculturais e suas derivações político-sociais afetam, igualmente, as gerações. Deste modo, verifica-se, na contemporaneidade, um cenário de pluralidades, no qual se observam, por exemplo, o desemprego em seus aspectos estrutural e conjuntural; fluxo de migrantes e refugiados em busca de melhores condições de vida; violência generalizada contra crianças, idosos, etnias e gênero, por meio de ações terroristas/fundamentalistas ou não; e, ainda, a presença das inovações tecno-científicas e as consequências do fenômeno da globalização que impactam o modus vivendi dos sujeitos, (re)estabelecendo uma interconexão à dinâmica das relações geracionais.

Tais relações não são consideradas como um fato social despercebido, pelo contrário, no âmbito da Biblioteconomia, ressalta-se a participação da American Library Association (ALA) que, por intermédio do Center for the 
Future of Libraries, apontou algumas tendências relacionadas às bibliotecas e às comunidades nas quais se inserem, e dentre essas se destacam três aspectos emergentes, entre outros, vinculados diretamente aos ciclos da vida humana: envelhecimento da população; crescente número de jovens adultos; e a presença dos nativos digitais (CENTER FOR THE FUTURE OF LIBRARIES, c2016). Assim, tais segmentos geracionais podem coexistir em um mesmo ambiente informacional e, consequentemente, demandar complexos serviços e produtos informação, aprendizagem e entretenimento -, por meio de diferenciadas atividades e inovações nas práticas das bibliotecas, uma vez que envolvem indivíduos com diferentes idades, costumes, conflitos e valores.

Mediante tais complexidades, a informação transforma-se em um instrumento político e, consequentemente, de poder. Em decorrência, as unidades prestadoras de serviços de informação tornam-se um canal de comunicação em que se opera a intermediação entre os sujeitos e os fluxos informacionais, por meio de suas práticas, entre as quais se destaca a educação de usuários. Tal prática, ainda existente, encontra-se associada ao contexto das bibliotecas, principalmente, naquelas vinculadas às instituições de ensino e tem a pretensão de desenvolver comportamentos apropriados e habilidades quanto ao uso da biblioteca e aos recursos informacionais disponíveis (BELLUZZO, 1989), consequentemente, esperando-se que os sujeitos tornem-se mais autônomos nos processos de busca e uso da informação, para a apreensão do mundo e, ao mesmo tempo, para suas ações e decisões na sociedade.

Assim, identificar as conexões históricas e sociais entre os estudos de gerações e as práticas planejadas, no uso dos recursos informacionais, desenvolvidas pelas bibliotecas configura-se como objetivo deste trabalho.

\section{Estudos de usuários - Formação de usuários}

Desde os primeiros trabalhos nomeados como estudos de usuários, principalmente a partir dos anos de 1940, tem-se verificado, por meio de artigos de revisão da literatura, evoluções tanto em seus aspectos conceituais, metodológicos, quanto pelas técnicas de pesquisa. E, ainda, o estabelecimento de modelos orientados, que buscaram estudar o comportamento de coletivos 
sociais em relação à informação, como, entre outros, os de Belkin (1980), Wilson (1981), Krikelas (1983), Dervin (1983), Taylor (1986), Ellis (1989) e Kuhlthau (1991). Esse processo evolutivo parece ser ordenado em função das transformações sociais, econômicas e tecnológicas - de uma sociedade rígida e estática para uma sociedade flexível e competitiva - que afetam os comportamentos humanos, notadamente, em relação à informação e, consequentemente, aos ambientes informacionais.

Nestes últimos, tais transformações provocam, de certa forma a (re)formulação, o desenvolvimento e/ou a implementação de inovações não só nos produtos e serviços de informação, mas também, nas diversificadas formas de gestão nas organizações, especificamente, naquelas voltadas à prestação de serviços de informação. Nessa dimensão, o estudo de usuários pode ser considerado, conforme Amaral, como um campo de conhecimento que "[...] possibilita a análise dos fenômenos sociais e humanos relacionados com os diversos aspectos e características da relação do usuário com a informação em suas ações, comportamentos e práticas informativas." (AMARAL, no prelo). Tornam-se relevantes, visto que permitem o entendimento da relação dos atores sociais em seus múltiplos contextos e nas formas de interação com a informação.

Tal interação encontra-se associada à compreensão do entendimento do processo de busca e uso da informação por parte do usuário. Assim, infere-se que a formação desse se vincula à aquisição de habilidades e conhecimentos quanto ao acesso, recuperação e, também, no uso dos produtos e serviços que se encontram em complexos suportes e nos mais diversificados ambientes informacionais. Logo, a formação de usuários vincula-se, conforme Hernández Salazar (1998, p. 11, tradução nossa), a um

[...] processo de intercâmbio de experiências ou saberes significativos sobre o uso da informação, de modo que a pessoa que a usa, de acordo com o processo cognitivo, perceba a importância da informação e adquira formas de saber fazer ou de resolver problemas relacionados com o acesso e uso da informação.

Sanz Casado (1994) compreende, favoravelmente, a inter-relação entre os estudos de usuário e a formação de usuário. O autor destaca que os 
resultados desses estudos permitem planejar programas específicos de formação, com maior eficácia em relação às necessidades e aos interesses informacionais dos indivíduos, em contraposição àqueles amplos para grupos heterogêneos. $\mathrm{Na}$ perspectiva do processo de formação, isto é, de aprendizagem em relação ao trinômio busca, acesso e uso da informação, de forma que os indivíduos possam gerar novos conhecimentos e produtos, e, assim, fortalecer o desenvolvimento dos países. Neste sentido, de acordo com Wersig (1993), necessitam ser capacitados para sobreviver em ambientes de conhecimento e, desta forma, encontrarem seus próprios caminhos.

Le Coadic (2004) expressa sua preocupação quanto à inexistência de uma educação para a informação. Uma disciplina que permitisse a construção de habilidades para o domínio da mesma permitiria, conforme o autor, a inserção dos indivíduos na sociedade da informação, isto é, contribuiria para minimizar a diferença existente entre inforricos e infopobres. Daí a importância que se atribui a uma das aplicações dos estudos de usuários desenvolvidos nas unidades prestadoras de serviços de informação e, consequentemente, aos possíveis reflexos positivos para a sociedade.

Em recente pesquisa, Gomes (2016) verificou que, na trajetória histórico-discursiva, não é recente a preocupação, no campo disciplinar da Biblioteconomia, quanto à formação dos usuários da informação por meio de práticas relacionadas ao uso de recursos informacionais. Para o autor, com base nos estudos de Salony (1995), desde o século XVII, já havia uma inquietação dos profissionais vinculados às bibliotecas em realizar algum tipo de atividade voltada para o uso daquelas instituições. Tem-se o entendimento de que a biblioteca pode não só contribuir, mas também tornar-se um ambiente de aprendizagem, por meio dos mais variados materiais informacionais existentes (GOMES; DUMONT, 2015). Todavia, em suas análises Gomes (2016, p. 222, grifo do autor) identifica que

\footnotetext{
Independentemente da abordagem semântica e concepções histórico-conceituais, paradigmáticas e terminológicas dadas pelas pesquisas para as categorias de formação dos sujeitos alfabetização, aprendizagem, capacitação, competência, educação, habilidade, infoeducação, instrução, letramento, orientação, treinamento, dentre outras - que se relacionam com as bibliotecas, a
} 
Biblioteconomia possui uma longa tradição de pesquisas, como também a Ciência da Informação, que sustentam que isoladamente a biblioteca, em quaisquer níveis educacionais em que se encontre inserida, pode não contribuir de maneira significativa para a construção do processo de busca e uso da informação em espaços multirreferenciais de informação.

O autor deixa transparecer que, no cenário que envolve a formação de usuários, o empreendimento da colaboração que se possa instituir entre os profissionais da informação e os demais profissionais torna-se essencial para a construção de conhecimentos e habilidades relacionados à aprendizagem em informação.

\section{Gerações e formação de usuários da informação}

Sob o rótulo do termo gerações, várias pesquisas são realizadas para identificar comportamentos, consumo, conflitos, crenças, estilos de vida, interesses, preferências e valores dos atores sociais que, possivelmente, tenham atributos que diferenciem ou associem os indivíduos ou os grupos a partir de um processo histórico e social. Os aspectos conceituais sobre gerações são amplamente discutidos por meio das análises sociológicas, principalmente, por meio de Karl Mannheim - considerado por diversos estudiosos como um representante significativo - o que forneceu um quadro pródigo sobre a teorização das gerações. Todavia, vale esclarecer que nesse artigo não se busca uma discussão teórica aprofundada em torno da polissemia sobre o conceito de geração, e sim estabelecer uma apreensão que forneça subsídios, os quais justifiquem o entrecruzamento da classificação geracional e a formação de usuários da informação.

Para Motta (2010), a questão etária constituiu-se não apenas como elemento de organização e integração social, como se percebe ao longo do desenvolvimento da humanidade, mas também como critério para discriminar, marginalizar e excluir. Ao tomar por base os estudos de Mannheim (1990), Motta fornece o seguinte entendimento para geração: “[...] representa a posição e atuação do indivíduo em seu grupo de idade e/ou de socialização no tempo." (MOTTA, 2010, p. 226). A autora acentua tal compreensão ao esclarecer que, no sentido macrossociológico, geração designaria 
[...] um coletivo de indivíduos que vivem em determinada época ou tempo social, têm aproximadamente a mesma idade e compartilham alguma forma de experiência ou vivência, ou têm a potencialidade para tal. (MOTTA, 2010, p. 229).

Assim, possivelmente, indicaria a confluência entre o etarismo e a dimensão histórica do processo social no qual os indivíduos encontram-se imersos.

Sob a ótica da teoria mannheimiana, Weller (2010) analisou, entre outros aspectos que distinguem uma sociedade marcada por mudanças geracionais, a necessidade de transmissão constante dos bens culturais acumulados. Ao destacar tal aspecto, permite empreender que as “[...] dificuldades existentes entre professores e alunos estão relacionadas às orientações ou visões de mundo distintas de cada geração [...]" (WELLER, 2010, p. 213). Assim, parece determinar um campo de tensão que, conforme a autora, pode ser superado pela interação ou troca de papéis, pois “[...] não é só o professor que educa o aluno, também o aluno educa o professor. As gerações estão em constante interação." (MANNHEIM, $1928^{1}$, p. 540 apud WELLER, 2010, p. 213).

Considerando a exposição de Weller (2010), acredita-se que, no contexto dos estudos que envolvem a informação, a colaboração entre os atores sociais configura-se como um possível eixo articulador entre os grupos geracionais. Um exemplo disso é o caso dos profissionais da informação que podem tornar-se um catalisador ao proporcionarem o acesso às diversas fontes de informação a fim de potencializar o conhecimento e harmonizar as tensões que possam existir independentemente da faixa etária. Dessa forma, a colaboração caracteriza-se como "[...] um processo em que duas ou mais pessoas trabalham em conjunto para integrar as informações, a fim de melhorar a aprendizagem dos alunos." (MONTIEL-OVERALL, 2005, p. 1), ou quaisquer outros grupos de indivíduos que necessitem de informação para desempenhar suas ações sociais.

Nesse sentido, destaca-se a pesquisa de Kuhlthau (1991) que identificou e classificou cinco estágios que os estudantes enfrentam para realizar o processo de busca e uso da informação - início (sentimentos: ansiedade e otimismo); exploração (sentimentos: incerteza, confusão e dúvida); formulação 
(sentimentos: confiança e clareza); coleta (sentimento: confiança); e apresentação (sentimentos: alívio, satisfação ou decepção). Observa-se que esses estágios que envolvem aspectos socioafetivos podem abranger qualquer grupo etário que se envolva em tal processo.

A investigação desenvolvida por Vechiato e Vidotti (2014), sobre o idoso como potencial usuário da informação, considera que o estudo relacionado ao comportamento informacional permite conhecer as práticas de busca e uso dos recursos informacionais (canais, fontes e suportes) de tal grupo. E, desse modo, possibilita ao profissional da informação estabelecer ações de formação e mediação frente às necessidades relacionadas à informação desse mesmo grupo.

Assim, considera-se que o processo de busca por informação

[...] pode ser incorporado aos programas de educação de usuários, para permitir que as pessoas tomem consciência de seu próprio processo de evolução e compreendam os sentimentos que afetam o uso da informação. (KUHLTHAU, 1991, p. 370).

Tais estágios estabelecidos por Kuhlthau (1991) podem contribuir na perspectiva do desenvolvimento de significados, para o aprendizado relacionado à informação durante a vida.

Para Barreto (1994, p. 1), a informação assume a possibilidade de referenciar "[...] o homem ao seu destino [...], e durante sua existência pela sua competência em elaborar a informação para estabelecer a sua odisseia individual no tempo e no espaço.". Tudo indica que a informação possibilita aos indivíduos atuarem no seu contexto social, de forma comprometida, com a construção de uma sociedade mais equânime e inclusiva.

Em estudo realizado por Bartalo e Santos Neto (2015, p. 227), com grupos de indivíduos não institucionalizados, considera-se que há uma "[...] competência que permeia a maneira de lidar com a informação [que] pode ser considerada imprescindível para todas as idades e gerações.”. Tal competência é entendida como competência em informação (CoInfo), logo, entende-se como um processo que possibilita aos indivíduos a interiorização e a exteriorização de conhecimentos, habilidades e atitudes associados à informação. 
Desse modo, parte-se da compreensão de que a formação de usuários da informação tem uma participação direta nos aspectos geracionais, logo, histórica e social, já que busca estabelecer uma mediação no fluxo espaço-temporal ao pretender possibilitar ao indivíduo maior autonomia no processo que envolve a busca, o acesso e o uso da informação para a escolha e tomada de decisões simples ou complexas. Além disso, visa a compreensão e a interação com o outro.

\section{Gerações: uma possível classificação dos usuários da informação}

Pesquisadores como Guinchat e Menou (1994) e Sanz Casado (1994) expõem, por meio da literatura, uma tipologia que se pode considerar clássica quanto aos usuários da informação, constituída em sua grande parte pelos seguintes grupos:
(1) pesquisadores e acadêmicos;
(2) estudantes;
(3) operários; administradores/gestores/planejadores e políticos; e, por fim, (5) cidadãos. Evidentemente, cada um desses apresentam atitudes, comportamentos e necessidades diferenciados em relação à informação, assim como, apresentam níveis socioeconômicos e etários distintos.

Ainda, foi possível identificar na literatura dois aportes que se coadunam em relação à classificação de gerações. O primeiro, em Prensky (2001), que emprega os termos nativos e imigrantes digitais, para descrever os indivíduos em relação ao acesso à informação, por meio das tecnologias digitais. $\mathrm{O}$ autor utiliza tais termos para explicar as diferenças socioculturais que se estabelecem entre aqueles que nasceram e cresceram na era digital e, desse modo, encontram-se imersos no universo Web - nativos digitais. Entretanto, aqueles que cresceram sem serem cercados por tecnologias fizeram a migração e convivem em ambientes digitais, sendo assim, conceituados como imigrantes digitais.

Vale ressaltar que diversas pesquisas apresentam classificações semelhantes ou sobrepostas para os usuários da Web. Tomaél et al. (2014) acreditam que, apesar de os nativos digitais estarem inseridos no mundo digital e virtual, a biblioteca exerce um papel essencial, pois pode auxiliá-los na seleção de fontes de informação ou, ainda, na estruturação da busca. Para os autores, as 
bibliotecas necessitam estabelecer uma harmonia em relação ao comportamento dessa geração, pois assim, conseguirão atender as necessidades dos mesmos.

O segundo aporte, de Cunha, Amaral e Dantas (2015), propõem que os usuários da informação possam ser identificados por gerações. Para tanto, indicaram um quadro amplo incluindo cinco classificações: Veteranos, Baby Boomers e as Gerações X, Y e Z.

\section{Percurso metodológico}

Trabalho classificado como exploratório, uma vez que busca, a partir de pesquisas já existentes, estabelecer novas perspectivas (HERNÁNDEZ SAMPIERI; FERNÁNDEZ COLLADO; BAPTISTA LUCIO, 2006). Utilizouse a pesquisa bibliográfica que, conforme Gil (2006), insere-se nos estudos exploratórios. Marconi e Lakatos (2010, p. 166) consideram que a bibliografia que se encontra disponível à sociedade sobre determinado tema "[...] não é mera repetição do que já foi dito ou escrito sobre determinado assunto, mas propicia o exame de um tema sob novo enfoque chegando a conclusões inovadoras.".

Desse modo, determinou-se: (1) o levantamento da literatura pertinente ao objeto de estudo nas áreas da Biblioteconomia, Ciência da Informação e da Sociologia. Para a identificação das fontes bibliográficas, foram consultados a Base de Dados Referenciais de Artigos de Periódicos em Ciência da Informação (BRAPCI) e o Portal de Periódicos da CAPES. Estabeleceu-se um recorte temporal e temático que coadunasse com o objetivo proposto e, dessa forma, determinaram-se nos idiomas português e inglês os seguintes termos para a busca: educação de usuários; instrução bibliográfica, orientação bibliográfica, estudos de usuários, competência em informação e geração. Ainda como parte da estratégia de busca, utilizaram-se truncamentos, conectores e caracteres que pudessem aperfeiçoar o processo de recuperação de fontes de informação e, consequentemente, o resultado da pesquisa. E, a partir disso, foram realizadas: (2) a seleção e análise de textos específicos com a temática; (3) identificação de contribuições relevantes; (4) sumarização dos argumentos selecionados; e (5) elaboração do texto. 
Todavia, vale esclarecer que, por meio da revisão de literatura, constatou-se que a evolução da educação/formação de usuários encontra-se vinculada, especificamente, aos Estados Unidos e à Inglaterra, e que, posteriormente, foram apropriadas pelos outros países, principalmente, os países terceiro-mundistas. Desta forma, a análise encontra-se ancorada, em sua grande parte, nas pesquisas realizadas naqueles países.

\section{Resultados}

Com base nas fontes de informação analisadas, foi possível estabelecer, para cada geração, as seguintes categorias: (1) coorte - "[...] designa um conjunto de indivíduos nascidos em um mesmo intervalo de tempo [...]" (MOTTA, 2010, p. 228); (2) características - refere-se às particularidades genéricas de um grupo de indivíduos, o (3) tempo histórico e social - entende-se como os fatos amplos ocorridos no contexto de cada geração e que proporcionaram impacto(s) à mesma; e, por fim, (4) formação dos usuários - a partir das categorias anteriores, traçar o entrecruzamento com as práticas desenvolvidas para a aprendizagem em informação. Utilizou-se a classificação geracional compreendida por veteranos, baby boomers e as gerações $\mathrm{X}, \mathrm{Y}$ e Z, por indicarem um universo amplo e diversificado.

\subsection{Veteranos ou geração silenciosa}

Quadro 1 - Veteranos ou geração silenciosa

\begin{tabular}{|l|l|l|}
\hline \multicolumn{1}{|c|}{ Coorte } & \multicolumn{1}{|c|}{ Características } & \multicolumn{1}{c|}{ Tempo histórico/social } \\
\hline Compreende o & Indivíduos educados & Abrange, principalmente, os \\
período de tempo & com disciplina, & reflexos da Primeira Guerra \\
iniciado entre & respeito às & Mundial e o término da \\
$1922 / 1925$ até & hierarquias, às leis e à & Segunda, marcado pela \\
1945. & ordem; no âmbito & reconstrução das economias. \\
& profissional apreciam & \\
& a consistência, o & \\
& comprometimento e a & \\
& lealdade (CUNHA; & \\
& AMARAL; & \\
& DANTAS, 2015; & \\
& PUC-SP, c2015). & \\
\hline
\end{tabular}

Fonte: Elaborado pelo autor. 
A formação de usuários reflete um pouco esse cenário, isto é, um esforço para o estabelecimento de programas que possibilitassem instrução quanto ao uso das bibliotecas. A educação de usuários não era uma atividade unânime realizada pelas faculdades e pelas universidades notadamente americanas. Várias experiências e inovações estavam sendo postas em prática para colocar os estudantes em contato com a biblioteca e seus recursos (SALONY, 1995; TIEFEL, 1995).

A educação de usuários como ação planejada não se constituía uma atividade comum no ensino superior (SALONY, 1995). A mesma constatação aplica-se às bibliotecas escolares (CAMPELLO, 2003). As estratégias para instruir os usuários para o uso da biblioteca e seus recursos concentravam-se em: visitas, cursos e por meio de manuais impressos; o foco era prover o usuário de juízo crítico sobre os materiais informacionais disponíveis e restritos às bibliotecas, basicamente livros e periódicos.

\subsection{Baby Boomers}

Quadro 2 - Baby Boomers

\begin{tabular}{|l|l|l|}
\hline \multicolumn{1}{|c|}{ Coorte } & \multicolumn{1}{|c|}{ Características } \\
40 e 60. & $\begin{array}{l}\text { Tempo histórico/social } \\
\text { Educados com } \\
\text { rigidez, valorizam } \\
\text { tanto o status como o } \\
\text { crescimento } \\
\text { profissional e são } \\
\text { fiéis à organização } \\
\text { em que exercem suas } \\
\text { atividades. Forte } \\
\text { engajamento político } \\
\text { (PUC-SP, c2015). }\end{array}$ & $\begin{array}{l}\text { Reconstruço e } \\
\text { transformações política, social } \\
\text { em virtude do período pós- } \\
\text { guerra. }\end{array}$ \\
\hline
\end{tabular}

Fonte: Elaborado pelo autor.

Neste período, a literatura apresenta que, no campo da informação, teóricos sustentam, inicialmente, a predominância do paradigma físico, isto é, a urgência no desenvolvimento de sistemas informatizados, para a organização da massa documental crescente - processamento e transmissão por meio de máquinas (ALMEIDA et al., 2007). Desse modo, fazendo acessível um acervo que começava a se ampliar de forma rápida, principalmente, no pós-guerra. 
Pesquisa e Desenvolvimento (P\&D) torna-se, sobretudo por meio da informação científica, palavra-chave nos programas e nos planos para crescimento e inovação em diversos países, ao tempo em que impulsiona o modelo capitalista. Tanto a produção, como a transferência e o acesso à informação manifestam-se como relevantes para o desenvolvimento econômico. Logo, uma necessidade de instruir tanto os estudantes de graduação como os de pós-graduação no uso das bibliotecas, visto que tal espaço não era percebido como fonte de informação para a geração de conhecimento pela sociedade (HURT, 1934).

No contexto dos estudos que envolvem a formação de usuários, desenvolve-se, no início dos anos de 1950, o serviço de instrução bibliográfica, com o objetivo de proporcionar ao usuário a compreensão no manuseio e na seleção de fontes de informação (CAMPELLO, 2003; KUHLTHAU, 1987). Patrícia Knapp foi uma representante significativa nessa época, pois defendia a integração da instrução da biblioteca no currículo e tarefas apoiadas em questionamentos e resolução de problemas (KNAPP, 1966).

Período marcado por reflexões e práticas complexas, entre as quais se destacam: a biblioteca como organismo multidimensional, cooperação entre bibliotecários e professores, avaliação no uso dos recursos informacionais e o emprego de tecnologias - filmes, transparências, instrução assistida por computador, entre outras (GOMES, 2016). Tal período pode ser identificado como centrado na construção de habilidades para o acesso à informação, uma vez que demanda informações atualizadas - artigos de periódicos, patentes, relatórios, publicações técnicas, dentre outras.

\subsection{Geração X}

Quadro 3 - Geração X

\begin{tabular}{|l|l|l|}
\hline \multicolumn{1}{|c|}{ Coorte } & \multicolumn{1}{|c|}{ Características } & \multicolumn{1}{c|}{ Tempo histórico/social } \\
\hline $\begin{array}{l}\text { Décadas de 60 e 70 } \\
\text { - filhos dos baby } \\
\text { boomers. }\end{array}$ & $\begin{array}{l}\text { Informalidade no } \\
\text { trabalho e menor } \\
\text { fidelização às } \\
\text { organizações, } \\
\text { aproximação com a } \\
\text { tecnologia e o }\end{array}$ & $\begin{array}{l}\text { Revoluções comportamentais } \\
\text { - sexual e racial. Acelerado } \\
\text { avanço científico e tecnológico } \\
\text { iniciado em anos anteriores. }\end{array}$ \\
\hline
\end{tabular}




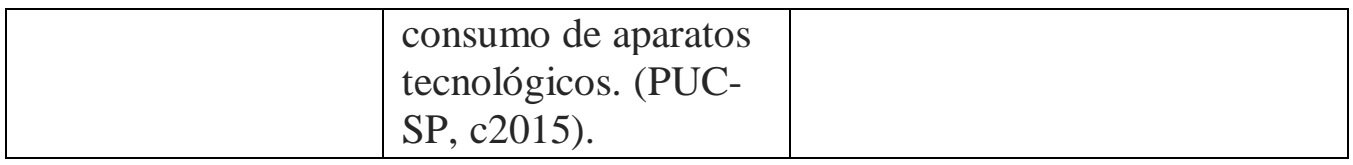

Fonte: Elaborado pelo autor.

Teóricos como Alvin Tofler, Daniel Bell, Peter Drucker, entre outros, começaram a arquitetar a perspectiva de uma nova sociedade. Nessa, a informação, o conhecimento e a tecnologia seriam possíveis recursos para o desenvolvimento econômico (GOMES, 2016). Dessa forma, constata-se forte impacto na formação de usuários, uma vez que se presencia nas bibliotecas a implantação de artefatos tecnológicos para o armazenamento e a recuperação da informação. Nesse sentido, instituem-se redes de cooperação para apoiar programas de educação de usuários.

O foco está no desenvolvimento de habilidades de pensar, de aprender a aprender e, também, de comunicar o conhecimento gerado (DAVIES, 1974), a fim de provocar mudança de comportamento nos indivíduos em relação à informação. Acrescenta-se o surgimento dos conceitos de information literacy e infostructure por Zurkowski (1974, 1984); o primeiro desencadearia novas abordagens teóricas em relação à aprendizagem, vinculada aos processos de busca e uso da informação nos anos posteriores, enquanto o segundo encontrarse-ia associado ao estabelecimento e fortalecimento da indústria da informação estadunidense.

\subsection{Geração Y}

Quadro 4- Geração Y

\begin{tabular}{|c|c|c|}
\hline Coorte & Características & Tempo histórico/social \\
\hline Entre 1980 e 1999. & $\begin{array}{l}\text { Indivíduos com } \\
\text { cultura competitiva e } \\
\text { imediatista; } \\
\text { necessitam estar } \\
\text { conectados por meio } \\
\text { das tecnologias; e } \\
\text { encontram-se } \\
\text { expostos à } \\
\text { hiperinflação de } \\
\text { informaçôes. } \\
\text { (CUNHA; }\end{array}$ & $\begin{array}{l}\text { Expansão e consolidação da } \\
\text { globalização, endurecimento } \\
\text { do capitalismo global, assim } \\
\text { como, em contrapartida, o } \\
\text { movimento de protestos e os } \\
\text { movimentos sociais. Forte } \\
\text { presença de computadores nos } \\
\text { âmbitos profissional, } \\
\text { doméstico e pessoal e o } \\
\text { impacto da Internet alterando } \\
\text { significativamente as relações }\end{array}$ \\
\hline
\end{tabular}




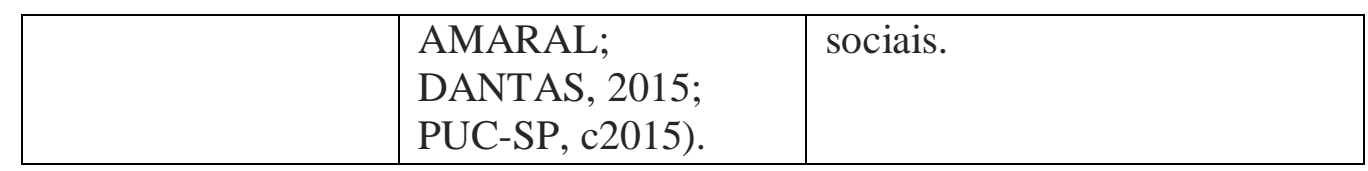

Fonte: Elaborado pelo autor.

Com relação às atividades de formação de usuários, verifica-se uma migração fundamental: anteriormente, ancoradas em materiais impressos, verifica-se a passagem à inclusão de acervos digitais, consequentemente, o uso crescente de tecnologias para aquela formação (aprendizado assistido por computador, tutoriais, entre outros). Como resultado, passou-se a inserir estratégias de busca, assim como, habilidades na seleção, avaliação e organização das informações recuperadas nas bases de dados (SALONY, 1995; TIEFEL, 1995).

Além disso, constata-se o surgimento de uma nova terminologia para designar os até então serviços destinados à educação de usuários, como: habilidades informacionais e alfabetização informacional (CAREGNATO, 2000), ao tempo em que se busca determinar quais as habilidades em informação que os estudantes deveriam dominar (CAMPELLO, 2003).

Período que se diferencia das décadas anteriores, uma vez que não se vincula mais a ensinar aos alunos a acessar os materiais disponíveis na biblioteca, e sim, começa a focar em conceitos, e como a informação pode ser utilizada nas disciplinas (HOPKINS, 1982). Tem-se a perspectiva da participação do(a) bibliotecário(a) para colaborar no desenvolvimento do pensamento crítico e reflexivo dos usuários, assim como de outras habilidades para melhorar a aprendizagem no decurso da vida, por meio da informação aprender a aprender.

Nessa época, outro aspecto relevante é o início do envolvimento dos(as) bibliotecários(as) com o movimento da competência em informação, assim como o desenvolvimento de modelos - The Big6, Plus Model, Alberta Model, entre outros. Isso visa auxiliar diversos segmentos para o processo de pesquisa e a construção de competências relacionadas à informação, possibilitando maior autonomia nos indivíduos (CAMPELLO, 2003; GOMES, 2016). 


\subsection{Geração Z}

Quadro 5 - Geração Z

\begin{tabular}{|c|c|c|}
\hline Coorte & Características & Tempo histórico/social \\
\hline 2000 em diante. & $\begin{array}{l}\text { Facilidade em lidar } \\
\text { com as tecnologias nas } \\
\text { atividades rotineiras - } \\
\text { estudar, trabalhar e } \\
\text { relacionar-se; } \\
\text { conectados às redes } \\
\text { sociais e com } \\
\text { possibilidades de } \\
\text { amplo acesso ao } \\
\text { conhecimento, não } \\
\text { fazem diferenciação da } \\
\text { vida online da offline, } \\
\text { Preferência por } \\
\text { contatos virtuais em } \\
\text { relação aos presenciais. } \\
\text { Entendem a } \\
\text { flexibilidade como } \\
\text { algo positivo tanto nos } \\
\text { estudos, como nas } \\
\text { futuras relações } \\
\text { trabalhistas. (PUC-SP, } \\
\text { c2015). }\end{array}$ & $\begin{array}{l}\text { Concentração do poder } \\
\text { político e econômico dos } \\
\text { países centrais em detrimento } \\
\text { dos periféricos, resultando } \\
\text { em guerras e conflitos, ações } \\
\text { terroristas e xenófobas. } \\
\text { Amplas discussões sobre o } \\
\text { meio ambiente e ecologia, } \\
\text { iniciadas em períodos } \\
\text { anteriores. Acirrada } \\
\text { competição entre mercados, } \\
\text { organizações e indivíduos. }\end{array}$ \\
\hline
\end{tabular}

Fonte: Elaborado pelo autor.

No campo tecnológico, encontram-se as inovações que revolucionaram a comunicação, e também, a armazenagem e o acesso à informação massificação do telefone celular com inúmeras funções, redes sociais, popularização da banda larga e a computação na nuvem, entre tantas outras.

No âmbito da temática formação de usuários, intensificam-se as pesquisas, os eventos e os documentos sobre a CoInfo em diversos países, considerando o desenvolvimento de conhecimentos, habilidades e atitudes relacionados à busca, ao uso e à comunicação da informação a partir de necessidades informacionais percebidas. Acentua-se a tendência na elaboração de programas colaborativos - bibliotecários, professores e outros profissionais. Dessa maneira, ações e/ou programas, não apenas presenciais, não se vinculam somente para busca e uso de materiais disponíveis nas bibliotecas, mas também em espaços multirreferenciais de informação. 


\section{Considerações finais}

Ressalta-se que a educação de usuários, por meio de suas contribuições teóricoconceituais, metodológicas e pragmáticas, recompõe uma trajetória cronológica que perpassa por gerações, indicando um empreendimento relacionado ao acesso e uso dos recursos informacionais. Desse modo, acredita-se no fortalecimento de uma formação e cultura informacional. A partir de uma perspectiva histórica, na qual se considera a multiplicidade de condições sociais, econômicas e políticas em diferentes momentos do tempo, as unidades prestadoras de serviços de informação, notadamente as bibliotecas, buscam harmonizar seus serviços ao se confrontarem com as necessidades da sociedade.

Constata-se um alinhamento entre os estudos de usuários e da educação e/ou da formação do mesmo que vai se alterando e/ou intensificando conforme as demandas desenhadas no cenário socioeconômico e tecnológico para determinadas classes geracionais. Subentende-se que, no contexto de cada geração, encontram-se indivíduos - crianças, jovens e adultos - que possam ser excluídos de uma formação voltada para a informação, em virtude de que há sociedades que, possivelmente, não apresentam em sua infraestrutura uma rede de bibliotecas públicas e escolares e que poderiam se colocar como espaços de ensino e aprendizagem e auxiliar em tal formação.

Destaca-se que a CoInfo torna-se um movimento, em diversos países, com a pretensão de possibilitar o aprendizado em contextos de mudanças tecnológicas, para lidar com o crescimento exponencial da informação em diversos aparatos. É nessa dimensão que a biblioteca poderia assumir papel de protagonista por meio de diversas ações planejadas, assim, constituindo-se um espaço de ensino-aprendizagem relacionado à informação.

\section{Referências}

ALMEIDA, Daniela Pereira dos Reis de et al. Paradigmas contemporâneos da ciência da informação: a recuperação da informação como ponto focal. Revista Eletrônica Informação e Cognição, v. 6, n. 1, p. 16-27, 2007. Disponível em: <http://www2.marilia.unesp.br/revistas/index.php/reic/article/view/745>. Acesso em: 9 nov. 2016. 
AMARAL, Sueli Angélica do. Mercadotecnia y estudios de usuarios para identificar y satisfacer las necesidades de información. In: SEMINARIO DE INVESTIGACIÓN SOBRE USUARIOS DE LA INFORMACIÓN, 9., 2014, Tuxtla Gutiérrez. No prelo.

BARRETO, Aldo de Albuquerque. A questão da informação. São Paulo em Perspectiva, São Paulo, v. 8, n. 4, p. 1-10, 1994.

BARTALO, Linete; SANTOS NETO, João Arlindo dos. A concepção de competência em informação das diferentes gerações de pessoas. In: SIMEÃO, Elmira Luzia Melo Soares; BELLUZZO, Regina Célia Baptista (Org.).

Competência em informação: teoria e práxis. Brasília: Universidade de Brasília, 2015. p. 217-230.

BELKIN, Nicholas J. Anomalous states of knowledge as a basis for information retrieval. The Canadian Journal of Information Science, [S.1.], v. 5, p. 133143, 1980.

BELLUZZO, Regina Célia Baptista. Educação de usuários de bibliotecas universitárias: da conceituação e sistematização ao estabelecimento de diretrizes. 1989. 107 f. Dissertação (Mestrado em Ciências da Comunicação) Escola de Comunicações e Artes, Universidade de São Paulo, São Paulo, 1989.

CAMPELLO, Bernadete. O movimento da competência informacional: uma perspectiva para o letramento informacional. Ciência da Informação, Brasília, v. 32, n. 3, p. 28-37, set./dez. 2003. Disponível em:

<http://revista.ibict.br/ciinf/index.php/ciinf/article/view/26/22>. Acesso em: 10 dez. 2016.

CAREGNATO, Sônia Elisa. O desenvolvimento de habilidades informacionais: o papel das bibliotecas universitárias no contexto da informação digital em rede. Revista de Biblioteconomia \& Comunicação, Porto Alegre, v. 8, p. 47-55, jan./dez. 2000.

CENTER FOR THE FUTURE OF LIBRARIES. Trends. Chicago: ALA, c2016. Disponível em:

<http://www.ala.org/transforminglibraries/future/trends>. Acesso em: 13 nov. 2016.

CUNHA, Murilo Bastos da; AMARAL, Sueli Angélica do; DANTAS, Edmundo Brandão. Manual de estudo de usuários da informação. São Paulo: Atlas, 2015.

DAVIES, R. A. Educating library users in the senior high school. In: LUBANS, J. Educating the library user. New York: R. R. Bowker, 1974. p. 39-52.

DERVIN, Brenda. An overview of sense-making research: Concepts, methods and results to date. International Communication Association Annual 
Meeting. Dallas, 1983. 72 p. Disponível em: <http://communication.sbs.ohiostate.edu/sense-making/art/artdervin83.html>. Acesso em: 21 maio 2017.

ELLIS, David. Behavioral approach to information retrieval system design. Journal of Documentation, London, v. 45, n. 3, p. 171-212, 1989.

GIL, Antônio Carlos. Métodos e técnicas de pesquisa social. 5. ed. São Paulo: Atlas, 2006.

GOMES, Marcos Aurélio. Da educação de usuários à construção de competência em informação no contexto das bibliotecas das universidades federais: um estudo a partir da Universidade Federal de Alagoas e Universidade Federal de Minas Gerais. 2016. Tese (Doutorado em Ciência da Informação) Escola de Ciência da Informação, Universidade Federal de Minas Gerais, Belo Horizonte, 2016.

GOMES, Marcos Aurélio; DUMONT, Lígia Maria Moreira. Possíveis relações entre o uso de fontes de informação e a competência em informação.

TransInformação, Campinas, v. 27, n. 2, p. 133-143, maio/ago. 2015.

Disponível em: <http://periodicos.puc-

campinas.edu.br/seer/index.php/transinfo/article/view/2924/1962>. Acesso em: 28 jul. 2016.

GUINCHAT, Claire; MENOU, Michel. Introdução geral às ciências e técnicas da informação e documentação. Brasília: IBICT, 1994.

HERNÁNDEZ SALAZAR, Patricia. La formación de usuarios de información en instituciones de educación superior. México: UNAM, Centro Universitario de Investigaciones Bibliotecológicas, 1998.

HERNÁNDEZ SAMPIERI, Roberto; FERNÁNDEZ COLLADO, Carlos; BAPTISTA LUCIO, María del Pilar. Metodologia da pesquisa. 3. ed. São Paulo: McGraw Hill, 2006.

HOPKINS, Frances. A century of bibliographic instruction: professional and academic legitimacy. College and Research Libraries, Chicago, v. 43, n. 3, p. 192-198, May 1982. Disponível em:

<https://www.ideals.illinois.edu/bitstream/handle/2142/40381/crl_43_03_192_o pt.pdf?sequence=2>. Acesso em: 14 dez. 2016.

HURT, Peyton. The need of college and university instruction in the use of the library. Library Quarterly, Chicago, v. 4, n. 3, p. 436-438, July 1934. Disponível em: <http://www.jstor.org/stable/4302093>. Acesso em: 10 mar. 2017.

KNAPP, Patricia B. The Montieth College library experiment. New York: Scarecrow Press, 1966. 
KRIKELAS, James. Information seeking behavior: patterns of academic researchers. Drexel Library Quaterly, Philadelphia, v. 19, p. 5-20, 1983.

KUHLTHAU, Carol Collier. An emerging theory of library instruction. School Library Media Quarterly, Chicago, v. 16, n. 1, p. 13-18, 1987.

KUHLTHAU, Carol Collier. Inside the process: information seeking from the user's perspective. Journal of the American Society for Information Science, New York, v. 42, n. 5, p. 361-371, 1991. Disponível em:

<http://ptarpp2.uitm.edu.my/silibus/insidesearch2.pdf>. Acesso em: 10 jul. 2016.

LE COADIC, Yves. A ciência da informação. 2. ed. rev. atual. Brasília: Briquet de Lemos, 2004.

MANNHEIM, Karl. O problema das gerações. In: MANNHEIM, Karl.

Sociologia do conhecimento. Porto: RES-Editora, 1990. v. 2, p. 115-176.

MARCONI, Marina de Andrade; LAKATOS, Eva Maria. Fundamentos de metodologia científica. 7. ed. São Paulo: Atlas, 2010.

MONTIEL-OVERALL, Patricia. Toward a theory of collaboration for teachers and librarians. School Library Media Research, v. 8, 2005. Disponível em: <http://www.ala.org/aas1/aaslpubsandjournals/slmrb/slmrcontents/volume82005/ theory\#theoretical>. Acesso em: 10 jul. 2016.

MOTTA, Alda Britto da. A atualidade do conceito de gerações na pesquisa sobre o envelhecimento. Revista Sociedade e Estado, Brasília, v. 25, n. 2, p. 225-249, maio/ago. 2010.

PRENSKY, Marc. Digital natives, digital immigrants. On the Horizon, [Bradford], v. 9, n. 5, p. 1-6, Oct. 2001. Disponível em:

<http://www.marcprensky.com/writing/Prensky\%20-

\%20Digital\%20Natives,\%20Digital\%20Immigrants\%20-\%20Part1.pdf>. Acesso em: 13 jun. 2016.

PONTIFÍCIA UNIVERSIDADE CATÓLICA DE SÃO PAULO. Entendendo as gerações Veteranos, Boomers, X e Y. c2015. Disponível em:

$<$ http://www.pucsp.br/estagios/entendendo-geracoes-veteranos-boomers-X-e-y>. Acesso em: 15 dez. 2016.

SALONY, Mary F. The history of bibliographic instruction: clanging trends from books to the electronic world. The Reference Librarian, [S.1.], v. 24, n. 51/52, p. 31-51, 1995. Disponível em:

<http://dx.doi.org/10.1300/J120v24n51_06>. Acesso em: 15 dez. 2015.

SANZ CASADO, Elias. Manual de estúdios de usuários. Madrid: Pirámide, 1994. 
TAYLOR, Robert S. Value-added processes in information systems. Norwood: Ablex Publishing, 1986.

TIEFEL, Virginia. M. Library user education: examining its past, projecting its future. Library Trends, Illinois, v. 44, n. 2, p. 318-38, Fall. 1995. Disponível em:

<https://www.ideals.illinois.edu/bitstream/handle/2142/8026/librarytrendsv44i2 h_opt.pdf?sequence=1>. Acesso em: 11 nov. 2016.

TOMAÉL, Maria Inês et al. Práticas de inovação do bibliotecário no ambiente virtual. Encontros Bibli, Florianópolis, v. 19, n. 39, p. 83-112, jan./abr. 2014. Disponível em: <https://periodicos.ufsc.br/index.php/eb/article/view/15182924.2014v19n39p83>. Acesso em: 10 jun. 2016.

VECHIATO, Fernando Luiz; VIDOTTI, Silvana Aparecida Borsetti Gregorio. Idoso como usuário da informação. In: CASARIN, H. C. S. (Org.). Estudos de usuários da informação. Brasília: Thesaurus, 2014. p. 97-125.

WELLER, Wivian. A atualidade do conceito de gerações de Karl Mannheim. Sociedade e Estado, Brasília, v. 25, n. 2, p. 205-224, ago. 2010. Disponível em:

<http://www.scielo.br/scielo.php?script=sci_arttext\&pid=S010269922010000200004\&lng=en\&nrm=iso>. Acesso em: 23 dez. 2016.

WERSIG, Gernot. Information science: the study of postmodern knowledge usage. Information Processing \& Management, Elmsford v. 29, n. 2, p. 229239, 1993.

WILSON, Thomas Daniel. On user studies and information needs. Journal of Documentation, London, v. 31, n. 1, p. 3-15, 1981.

ZURKOWSKI, P. G. Integrating America's infostructure. Journal of the American Society for Information Science, New York, v. 35, n. 3, p. 170-178, 1984.

ZURKOWSKI, P. G. Information services environment relationships and priorities. Washington: National Commission on Libraries and Information Science, 1974. (Related Paper, n. 5). Disponível em:

<http://files.eric.ed.gov/fulltext/ED100391.pdf.>. Acesso em: 10 nov. 2016.

\section{Generation studies and users' formation}


Abstract: It aims to identify the historic and social connections between the generation studies and the practices developed in the use of information resources by libraries. It is an exploratory study with special attention to bibliographic research. We established four categories: cohort; characteristics; historic and social time; and users' formation. After considering these categories, we designed each generation class: seniors, baby boomers and generation $\mathrm{X}, \mathrm{Y}$ and $\mathrm{Z}$. We concluded that each generation class indicates, in a certain period of time, a possible direct match with the formation of information users which is linked to a socioeconomic demand.

Keywords: Users' education. Users' studies. Users' formation.

Recebido em: 03/01/2017

Aceito em: 21/03/2017

1 MANNHEIM, Karl. Das problem der generationen. In: MANNHEIM, Karl. Wissenssoziologie. Neuwied: Luchterhand, 1928. p. 509-565. Apud Weller (2010). 